\title{
Durability Probabilistic Evaluation of RC Structures Subjected to Chloride Ion
}

\author{
Han-Seung Lee ${ }^{1}$, Mohamed A. Ismail1 ${ }^{1,}$, Mohd Warid Hussin ${ }^{2}$ \\ ${ }^{1}$ School of Architecture \& Architectural Engineering, Hanyang University, Ansan, S. Korea \\ ${ }^{2}$ Construction Research Centre (UTM CRC), Institute for Smart Infrastructure and Innovative \\ Construction, Universiti Teknologi Malaysia, 81310 UTM Johor Bahru, Johor, Malaysia \\ *Corresponding Author Email: mismail@hanyang.ac.kr, phone: +82-31- 4005181, fax: +82-31- 4368169
}

\begin{abstract}
Chloride attack on concrete structures is becoming a primary factor that deteriorates the durability of concrete structures. For this reason, research has been conducted on chloride ion penetration and diffusion. This research produced an accurate durability life prediction through reliability assessments and proposes a prediction method for the chloride ion diffusion coefficient of a concrete applied assessment program for reliability. As a result, test materials were fabricated using different admixtures, and chloride ion diffusion coefficient was calculated by applying an RCPT test at each equivalent age. Based on the results, reliability prediction formulas were indicated through the reliability analysis for a durability life design using a Monte Carlo method. In addition, results were verified through comparisons and analysis using the proposed formula with the investigated data for chloride ion diffusion.
\end{abstract}

Keywords - Evaluation of durability life, Chloride ion diffusion coefficient, Monte Carlo method.

\section{INTRODUCTION}

It is widely known that the ingress of chloride ions constitutes a major source of durability problems affecting reinforced concrete structures that are exposed to saline environments. Once a sufficient quantity of chloride ions has accumulated around the embedded steel, pitting corrosion of the metal is liable to occur unless the environmental conditions are strongly anaerobic. In the design of concrete structures, the influence of chloride ingress on service life must be considered [Metha 2006; Papadakis 2000; Nielsen et al. 2003; Han 2007; Song et al. 2007].

The common service life model for the chloride induced corrosion of reinforcing steel in concrete involves two time periods. The first is the time for chloride diffusion until a sufficient concentration of chlorides is available at the reinforcing bar depth to initiate corrosion. The second is the time for corrosion damage (from initiation to cracking and spalling of the cover concrete) to the end of functional service life.

An apparent diffusion process, based on Fick's second law, can be used to model the time for chloride to reach and initiate corrosion, where first repair and rehabilitation at reinforcing steel depths will take place. When solved for the condition of constant surface chloride and a one-dimensional infinite depth, Fick's second law takes the following form [Kim et al. 2007]:

$$
C(x, t)=C_{0}\left(1-\operatorname{erf}\left(x / \sqrt{4 * D_{C}^{*} t}\right)\right)
$$

Where $C(x, t)$ is chloride concentration at depth and time; $C_{0}$ is surface chloride concentration; $D_{C}$ is apparent chloride ion diffusion coefficient; $t$ is time for diffusion; $x$ is concrete cover depth and erf is statistical error function. When $C(x, t)$ is set equal to the chloride corrosion initiation concentration and Eq. (1) is solved for $t$, the time for the diffusing chloride ions reaches rebar and initiates corrosion. However, for a given real condition, the values of $C(x, t), C_{0} \quad D_{C}$ and $x$ are random variables, each with their own statistical distributions, means, and variances. A solution to Eq. (1) for the time of diffusion should include the probabilistic nature of the input variables [Kirkpatrick et al. 2002; Enright and Frangopo 1998]. The time for corrosion damage to the end of functional service life is also a random variable and depends on the corrosion rate, concrete cover depth, reinforcing steel bar spacing, and size [Liu and Weyers 1998]. To predict the whole service life, the probabilistic nature of these variables should also be considered.

One common modern statistical technique is called Monte Carlo simulation. Monte Carlo is a general class of repeated sampling methods, where a desired response is determined by repeatedly solving a mathematical model using values randomly sampled from probability distributions of the input variables [Kalos and Whitlock 1986]. 


\section{SUMMARY OF CHLORIDE PENETRATION TEST}

\section{A. Experimental Program}

Mineral components for improvement of chloride blocking property were tested in the same environment. To examine diffusion blocking properties, Rapid Chloride Penetration Test (RCPT) was done. Configurations of test are presented in Table 1. Water-binding material ratio has two levels: $40 \%$ and $50 \%$. Fly Ash (FA), Blast furnace Slag (BS), Silica Fume (SF) and Meta Kaolin (MK) were used in 3 different levels.

Table 1. Dimensions of various fins

\begin{tabular}{|c|c|c|c|c|c|}
\hline Water- binding material ratio (\%) & \multicolumn{2}{|c|}{ Admixture type } & $\begin{array}{c}\text { Admixture } \\
\text { replacement ratio }\end{array}$ & Measurement & Measurement aging \\
\hline \multirow{5}{*}{40,50} & Non-blending & Designation & - & \multirow{5}{*}{$\begin{array}{l}\text { Compressive } \\
\text { strength }\end{array}$} & \multirow{5}{*}{$7,28,56,91$} \\
\hline & Fly ash & FA & $10,20,30$ & & \\
\hline & $\begin{array}{c}\text { Blast-furnace } \\
\text { slag }\end{array}$ & BS & $30,50,70$ & & \\
\hline & Silica fume & SF & $5,10,15$ & & \\
\hline & MetaKaolin & MK & $5,10,15$ & & \\
\hline
\end{tabular}

Table 2 shows composition of the plain concrete, without adding mineral components, to accomplish slump $18 \pm 2.5 \mathrm{~cm}$ and air entrained quantity, high efficiency $A E$ water reducing agent. For the test of chloride penetration, RCPT, which was proposed by Tang \& Nilsson, was referred to as illustrated in Fig. 1. Accordingly, each side of the cell is filled with $0.3 \mathrm{M}$ of sodium hydroxide $(\mathrm{NaOH})$ as anode and $3 \%$ of sodium chloride $(\mathrm{NaCl})$ as cathode. After that $30 \mathrm{~V}$ was applied to the cell. The test was maintained for 8 hours; then $0.1 \mathrm{~N}$ water solution of silver nitrate (AgNO3) was sprayed after the split test body. As a result, the color of affected area changed. The colored depth was measured by Vernier calipers. The chloride ion diffusion coefficient was calculated using Eq. (2) based on the measured results.

$$
\begin{aligned}
D=\frac{R T L}{z F U} & \cdot \frac{x_{d}-a \sqrt{x_{d}}}{t} \\
& \left(a=2 \sqrt{\frac{R T L}{z F U}} \cdot \operatorname{erf}^{-1}\left(1-\frac{2 c_{d}}{c_{0}}\right)\right)
\end{aligned}
$$

Where:

\begin{tabular}{l|l}
$\mathrm{D}$ & diffusion coefficient $\left(\mathrm{m}^{2} / \mathrm{s}\right)$ \\
\hline $\mathrm{z}$ & atomic value of ion $(\mathrm{z}=1$ for chloride ion $)$ \\
\hline $\mathrm{F}$ & Faraday constant $(96,481.04 \mathrm{~J} / \mathrm{Vmol})$ \\
\hline $\mathrm{U}$ & Voltage differences between positive and negative pulse \\
\hdashline $\mathrm{V}$ & gas constant $(8.314 \mathrm{~J} / \mathrm{Kmol})$ \\
\hline $\mathrm{T}$ & solution temperature $(\mathrm{K})$ \\
\hline $\mathrm{L}$ & specimen thickness $(\mathrm{m})$ \\
\hline$X_{d}$ & penetration depth of chloride ion $(\mathrm{m})$ \\
\hline $\mathrm{t}$ & test sustaining time \\
\hline $\mathrm{erf}$ & error function \\
\hline$c_{d}$ & chloride ion density at the section changed in color by \\
\hdashline$c_{0}$ & AgNO ${ }_{3}$ \\
\hline
\end{tabular}

Table 2. Composition of the plain concrete

\begin{tabular}{|c|c|c|c|c|c|}
\hline & \multirow{2}{*}{$\begin{array}{c}\text { Water- } \\
\text { cement } \\
\text { ratio (\%) }\end{array}$} & $\begin{array}{c}\text { Fine } \\
\text { aggregate } \\
\text { ratio (\%) }\end{array}$ & \multicolumn{4}{|c|}{ Unit weight $\left(\mathrm{kg} / \mathrm{m}^{3}\right)$} \\
\cline { 3 - 6 } & er & cement & $\begin{array}{c}\text { fine } \\
\text { aggregate }\end{array}$ & $\begin{array}{c}\text { coarse } \\
\text { aggregate }\end{array}$ \\
\hline 40 & 45.6 & 158 & 395 & 793 & 954 \\
\hline 50 & 47.7 & 158 & 316 & 861 & 951 \\
\hline
\end{tabular}




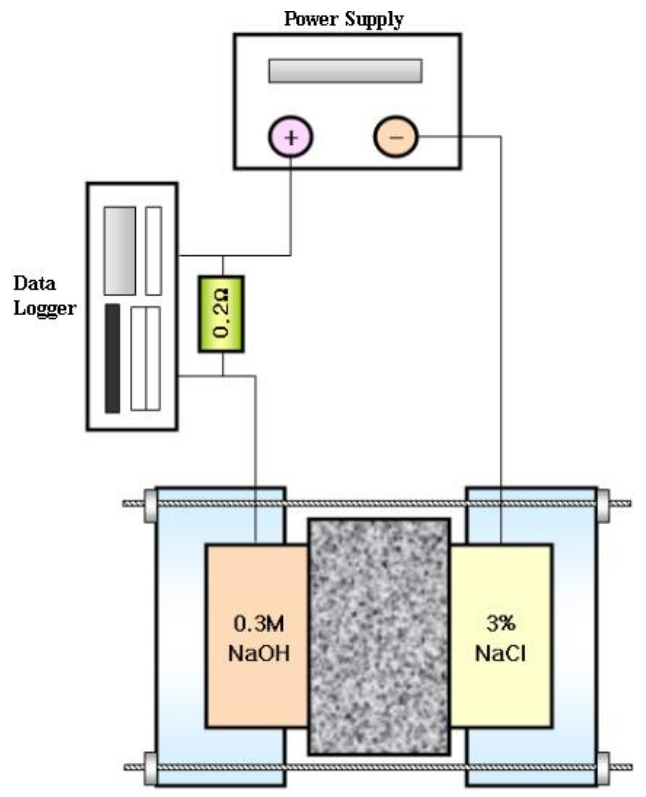

Fig .1. Diagram of chloride ion diffusion test equipment

Fig. 2 demonstrates the procedure of rapid chloride penetration test to examine chloride ion diffusion coefficient of chloride ion.
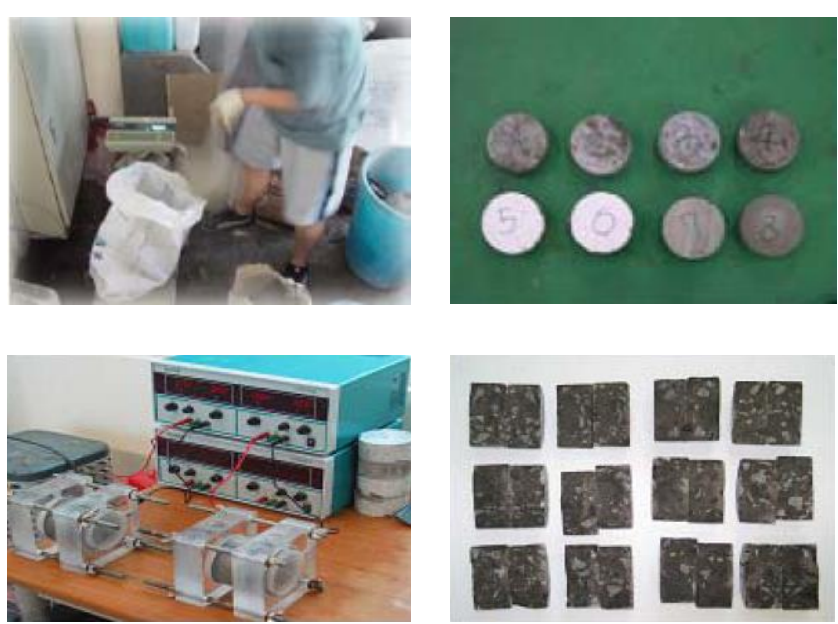

Fig .2. Procedure of rapid chloride penetration test

\section{EVALUATION OF PROBABILISTIC DURABILITY LIFE}

\section{A. In the latent period}

Corrosion in RC structure assumed to have occurred by the attack of salt. In this case, chloride concentration depth is determined by Eq. (3); it is also assumed that if chloride concentration is over the limits of $(1.2 \mathrm{~kg} / \mathrm{m} 3)$ at steel bar position then it is the end of service for the structure. In this study, durability of the structure in sea environment was statistically analyzed by Monte Carlo method. Table 3 shows the factors of statistical analysis. D0 is determined by RCPT, Dm is calculated by Eqs. (4a) and (4b) is used with chloride ion diffusion coefficient of chloride on the 28th day.

$$
\begin{aligned}
& x(t)=2 \operatorname{erf}^{-1}\left(1-\frac{C_{c r}}{C_{s}}\right) \cdot \sqrt{D_{m} t} \\
& D_{m}=\frac{D_{0}}{1-n}\left(\frac{t_{0}}{t}\right)\left(\mathrm{t}<\mathrm{t}_{c}\right) \\
& D_{m}=D_{0}\left[1+\frac{t_{0}}{t} \cdot \frac{n}{1-n}\right]\left(\frac{t_{0}}{t}\right)^{n}\left(\mathrm{t} \geq \mathrm{t}_{c}\right)
\end{aligned}
$$

\begin{tabular}{l|l} 
Where: & critical chloride content ion density at the beginning of \\
Corrosion $(\mathrm{kg} / \mathrm{m} 3)$
\end{tabular}

Table 3. Factors of statistical analysis

\begin{tabular}{|c|c|c|}
\hline Factor & Average & Standard deviation \\
\hline $\mathrm{D}_{0}$ & Test result & 1.2 \\
\hline $\mathrm{N}$ & Test result & 0.08 \\
\hline $\mathrm{d}(\mathrm{mm})$ & 40 & 7 \\
\hline $\mathrm{C}_{\mathrm{cr}}\left(\mathrm{kg} / \mathrm{m}^{3}\right)$ & 1.2 & 0.24 \\
\hline $\mathrm{C}_{\mathrm{s}}\left(\mathrm{kg} / \mathrm{m}^{3}\right)$ & 9 & 1.8 \\
\hline
\end{tabular}

\section{B. In the progress period}

Progress period means the period that starts after the beginning of corrosion and until the crack begins. In this period, if the corrosion quantity is larger than corrosion quantity when structure cracked, service year will be end. The amount of corrosion in steel bars can be calculated using Eq. (5).

$$
W(\text { spe })=I /(2 \mathrm{~F}) *\left[\mathrm{Fe}(\mathrm{OH})_{3}{ }^{1}\right] * t_{\text {corr }}
$$

$$
\left(I=0.025 * C(d, t)^{1.5}\right.
$$




$$
\left.\left.C(d, t)=C_{s}\left(1-\operatorname{erf}\left(\frac{d}{2 \sqrt{D_{m}} \cdot t}\right)\right)+C_{i}\right)\right)
$$

Where:

\begin{tabular}{|c|c|}
\hline 1 & corrosion current density $(\mu \mathrm{A} / \mathrm{cm} 2)$ \\
\hline$C(d, t)$ & $\begin{array}{l}\text { chloride ion density at the shield } \mathrm{d}(\mathrm{cm}) \text { and time } \\
\mathrm{t}(\text { year })(\mathrm{kg} / \mathrm{m} 3)\end{array}$ \\
\hline W(spe) & amount of steel bar corrosion $(\mathrm{g} / \mathrm{cm} 2)$ \\
\hline $\mathrm{F}$ & Faraday constant $(96500 \mathrm{C} / \mathrm{mol})$ \\
\hline $\mathrm{Fe}(\mathrm{OH}) 3$ & molecular weight of $\mathrm{Fe}(\mathrm{OH}) 3(\mathrm{II})(106.9 \mathrm{~g} / \mathrm{mol})$ \\
\hline$t_{\text {corr }}$ & $\begin{array}{l}\text { time lapse (years) from the beginning of the time } \\
\text { that exceeds the corrosion occurred critical } \\
\text { chloride content ion density }\end{array}$ \\
\hline $\mathrm{Ci}$ & $\begin{array}{l}\text { chloride ion density in the early stage } \\
(\mathrm{kg} / \mathrm{m} 3)(=0)\end{array}$ \\
\hline $\mathrm{Dm}$ & $\begin{array}{l}\text { Average chloride ion diffusion coefficient at } t \\
\text { (year) }(\mathrm{m} 2 / \mathrm{s})(\text { Eqs. 3a, 3b) }\end{array}$ \\
\hline
\end{tabular}

If the shield thickness is considered with factor $\mathrm{k}$, Eq. (5) will be expressed as Eq. (8). Eq. (9a) and Eq. (9b) considers diameter and shield thickness to get factor k. $\mathrm{C}(\mathrm{d}, \mathrm{t})$ is calculated by Eq. (7); Dm is calculated by (4a) and (4b) as a latent period. Ci assumed as 0 and steel bar diameter is assumed as $13 \mathrm{~mm}$. If corrosion calculated by Eq. (8) is larger than Wcr, which is calculated by Eq. (10), it is assumed that its service year has ended. As a process of the latent period, possibility of crack is calculated in the progress period.

$$
\begin{aligned}
& W=k * W(\text { spe }) \\
& k=1.0(3 * D \geq d) \\
& k=3 * D / d(3 * D<d) \\
& W c r=\frac{0.02 d}{3 D}
\end{aligned}
$$

Where:

\begin{tabular}{l|l} 
W & corrosion speed of steel bars \\
\hdashline $\mathrm{k}$ & shield parameter that affects corrosion speed \\
\hdashline $\mathrm{D}$ & steel bar diameter $(\mathrm{cm})$ \\
\hline $\mathrm{d}$ & shield thickness $(\mathrm{cm})$ \\
\hline $\mathrm{Wcr}$ & corrosion quantity when cracking begins $(\mathrm{g} / \mathrm{cm} 2)$ \\
\hline
\end{tabular}

\section{TEST ANALYSIS}

The 28th day compressive strength of this study is found to be between 30 40 MPa, as shown in Fig 3, whereas Fig. 4 the chloride ion diffusion coefficient of plain concrete for $\mathrm{W} / \mathrm{C}$ is between 0.4 and 0.5 . The estimation of the chloride ion diffusion coefficient DPC, can be produced using Eq. (11).

$D_{P C}=0.547 e^{3.95 \mathrm{~W} / \mathrm{C}}$

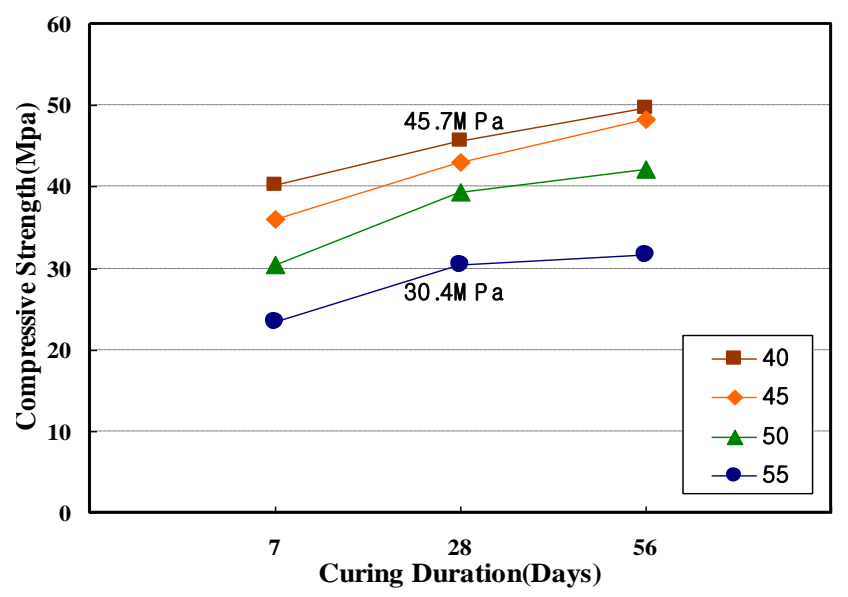

Fig .3. Compressive strength development with time

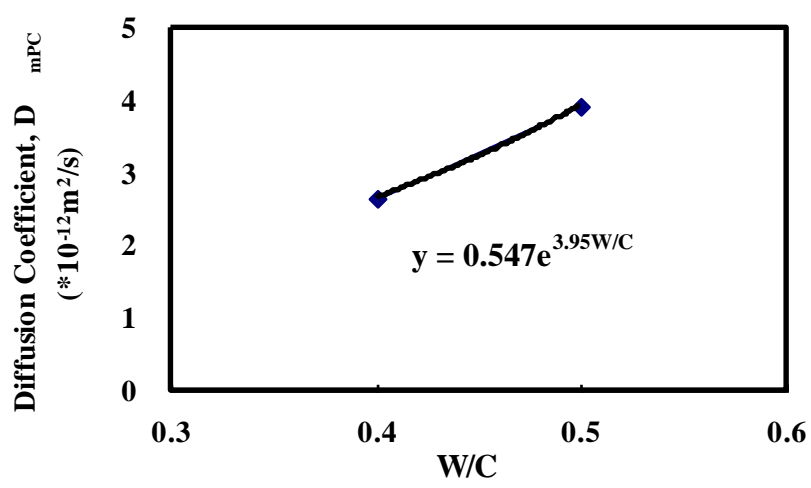

Fig .4. Diffusion coefficient of plain concrete W/C 0.4 and 0.5

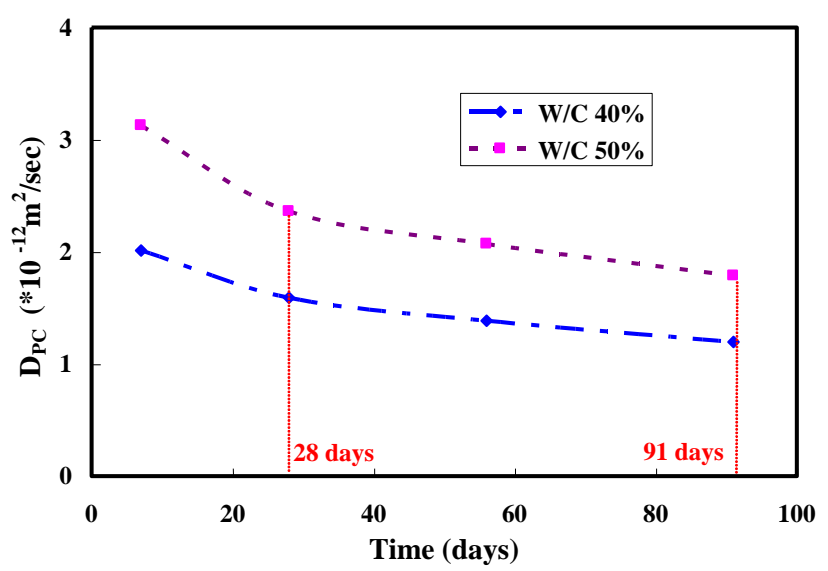

Fig .5. Diffusion coefficient according to time passage (W/C 0.4 and 0.5 ) 
In this study, chloride ion diffusion coefficient according to time passage (Fig. 5) was determined by RCPT and Eqs. (4a) and (4b). With this result, variation of diffusion coefficient was calculated. Fig. 6 shows diffusion coefficient ratio when the plain concrete was replaced by admixture. According to Fig. 6 , equation for determining the diffusion coefficient of each admixture was suggested in Table 4.

To estimate possibility of failure according to the time dependent coefficient variation, durability failure possibilities according to the service year was calculated when SF15\%, time dependent coefficient $\mathrm{n}=0,0.4$ and 0.8 (Fig. 7). Chloride ion diffusion coefficient can calculated by Eq. (12) when the concrete property according to the time dependent is considered. According to Eq. (13), induced by Eq. (12) and test result, the variation of time dependent parameter $[\mathrm{n}]$ is shown in Fig. 8.

$$
\begin{aligned}
& D(t)=D o\left(\frac{t_{0}}{t}\right)^{n} \\
& n=\log D o\left(\frac{t_{0}}{t}\right)^{D(t)}
\end{aligned}
$$
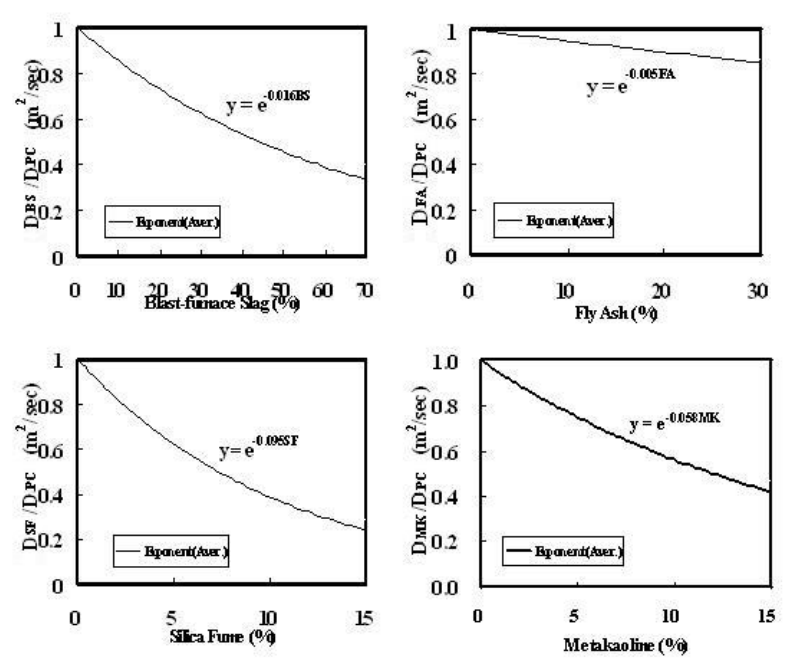

Fig .6. Type of admixture and substitution ratio

Table 4. Diffusion coefficient of each admixture

\begin{tabular}{|c|c|}
\hline Component & Equation $\left(\mathrm{m}^{2} / \mathrm{sec}\right)$ \\
\hline $\mathrm{BS}$ & $\mathrm{D}_{\mathrm{PC}} \cdot \mathrm{e}^{-0.016} \cdot \mathrm{SF}$ \\
\hline $\mathrm{FA}$ & $\mathrm{D}_{\mathrm{PC}} \cdot \mathrm{e}^{-0.005 \cdot \mathrm{SF}}$ \\
\hline $\mathrm{SF}$ & $\mathrm{D}_{\mathrm{PC}} \cdot \mathrm{e}^{-0.016} \mathrm{SF}$ \\
\hline $\mathrm{MK}$ & $\mathrm{D}_{\mathrm{PC}} \cdot \mathrm{e}^{-0.016} \cdot \mathrm{SF}$ \\
\hline
\end{tabular}

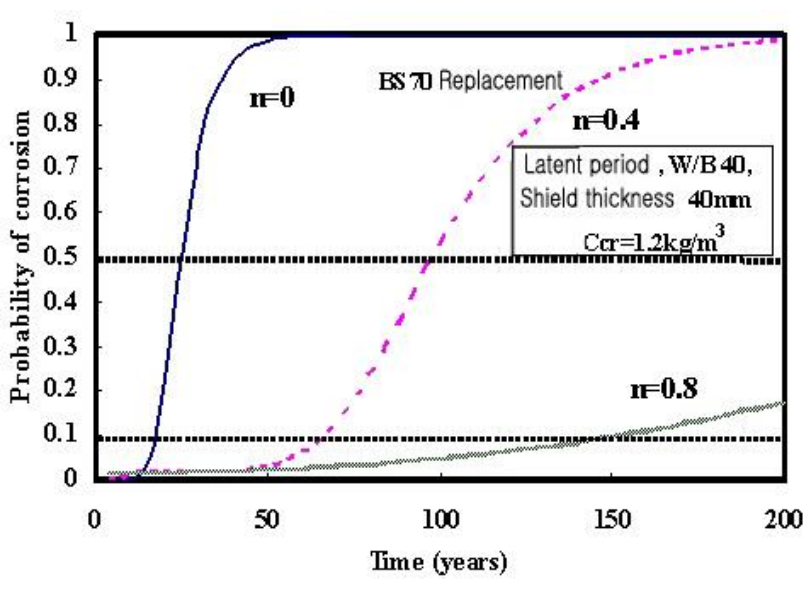

Fig .7. Durability failure possibilities according to the time dependent coefficient

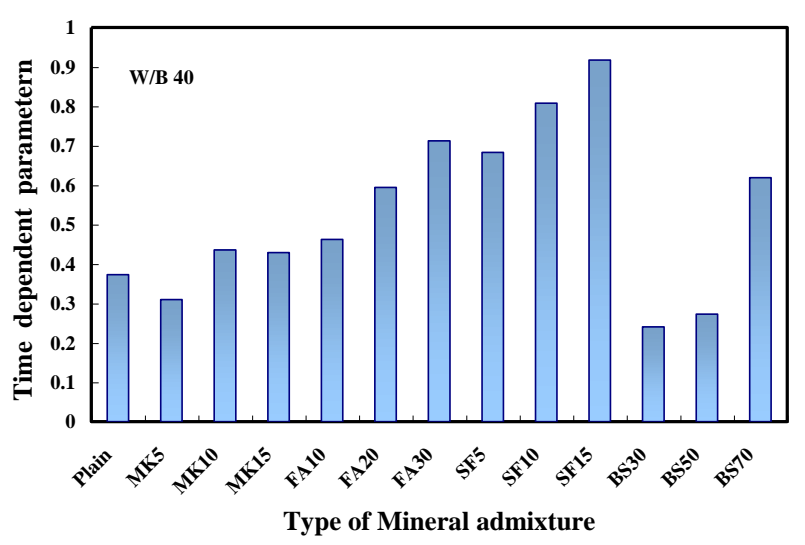

Fig .8. Time dependent parameter by type and quantity of mineral admixture

Probabilistic durability analysis for the latent period and the progress period were shown in Fig. 9. Meanwhile fly ash does not have any efficiency to improve durability, wherea blast furnace slag, silica fume and MetaKaolin do improve durability.

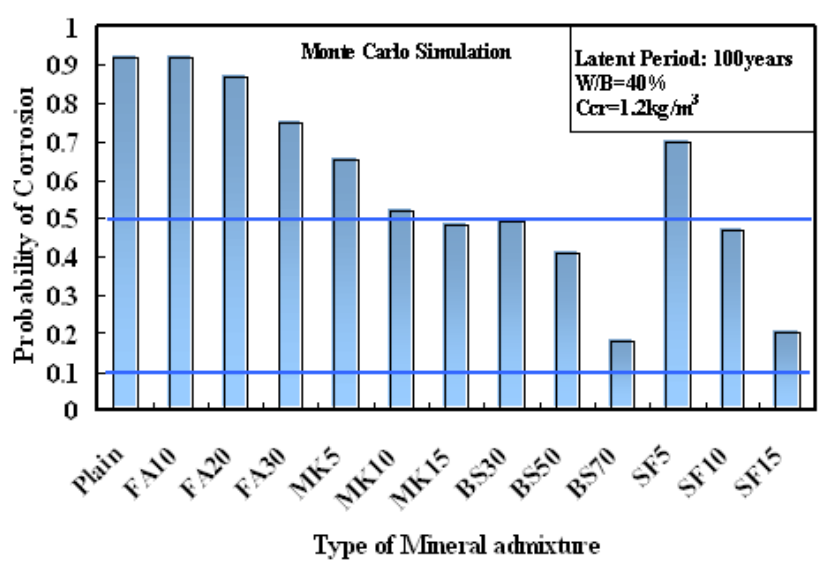

Fig .9. Possibility of durability failure by type and quantity of mineral admixture 
Fig. 10 shows the durability failure possibility according to shield thickness. If the shield thickness of steel bar is increased, distance from concrete surface to the steel is also increased. Consequently, resistance of chloride ion is increased and durability failure possibility is decreased. Fig. 11 shows durability failure possibility in latent period according to time. It is also replaced by SF $15 \%$ and BS $70 \%$ is most efficient to improve durability. The point of the possibility of durability failure will be $10 \%$ in the 80 th year.

Fig. 12 shows durability failure possibility when admixture type and replacement ratio are different. According to this graph, the deviation of admixture type is smaller than the deviation of replacement ratio. Durability failure possibility is also approximately $30 \%$ smaller.

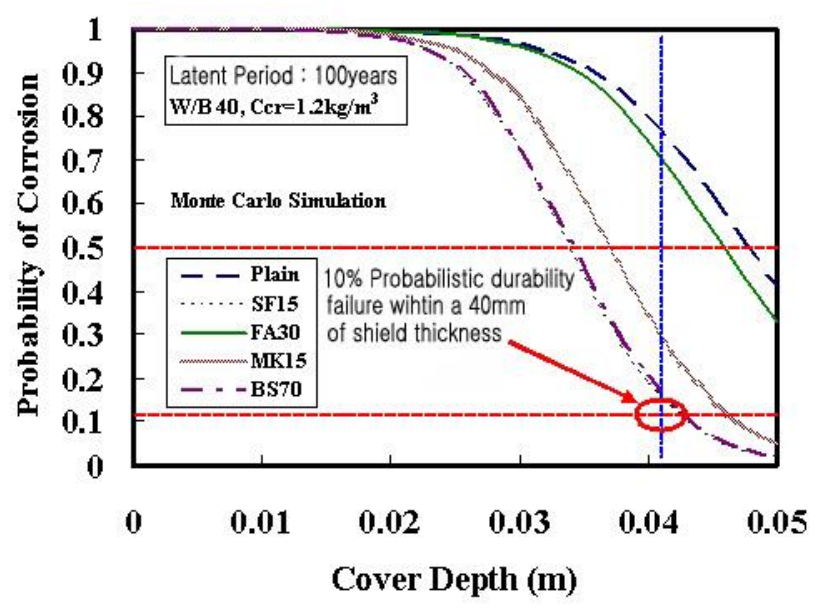

Fig .10. Durability failure possibility according to shield thickness

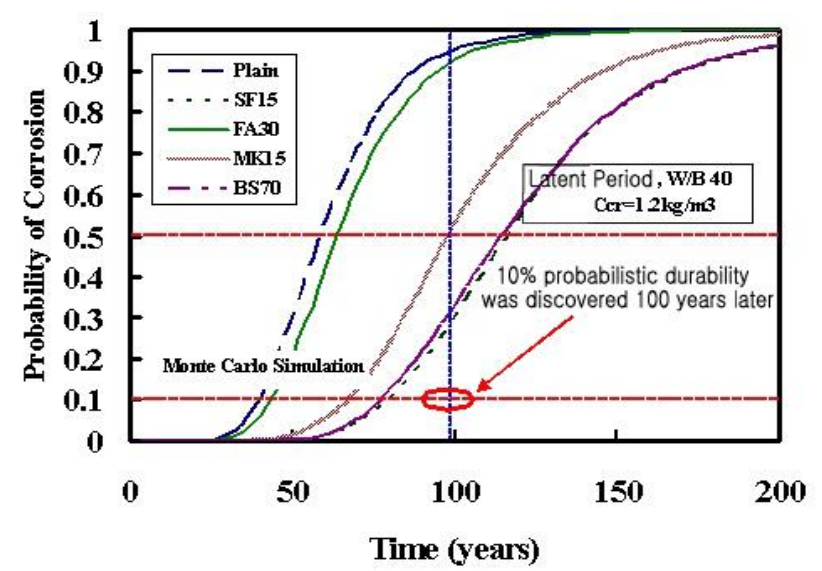

Fig .11. Durability failure possibility according to time

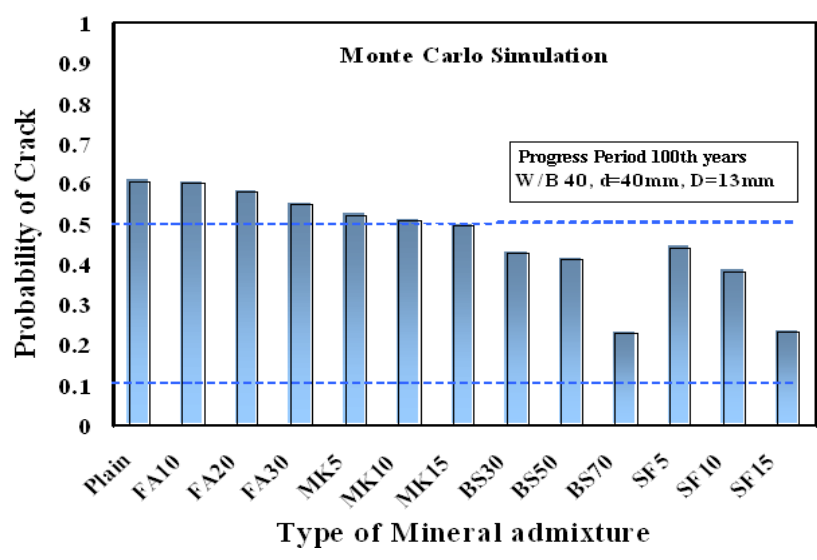

Fig .12. Durability failure possibility of admixture type and replacement variation

Fig. 13 presents the result of durability failure possibility according to the shield thickness, while Fig. 14 shows durability failure possibility in progress period according to time. In the latent period, nothing satisfied the durability failure possibility under $10 \%$ when shield thickness was $40 \mathrm{~mm}$ and over 100 years. However, when replaced by silica fume $15 \%$ and blast furnace slag $70 \%$, the durability failure possibility was reduced to $9 \%$ in the progress period, which satisfied possibility under $10 \%$. Other parameters have durability failure possibility over $30 \%$.

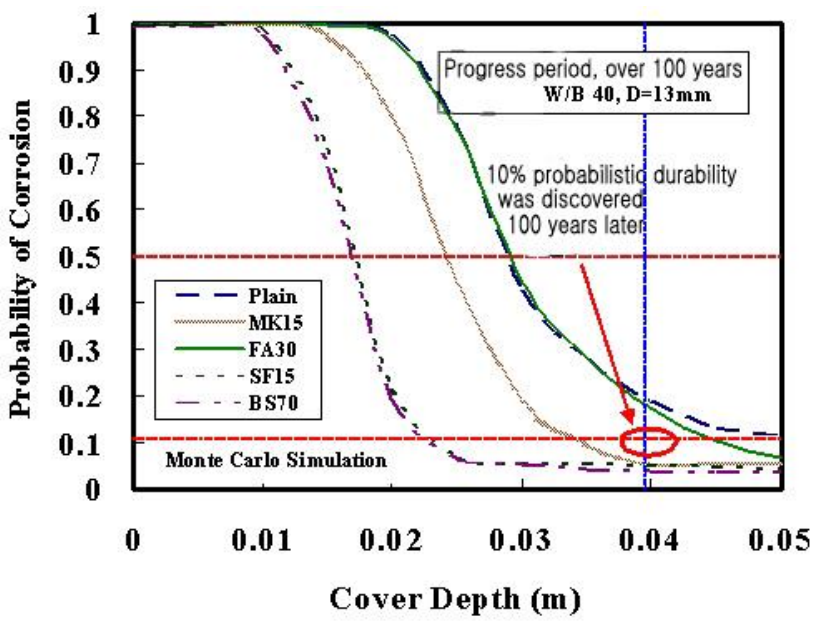

Fig .13. Durability failure possibility according to shield thickness 


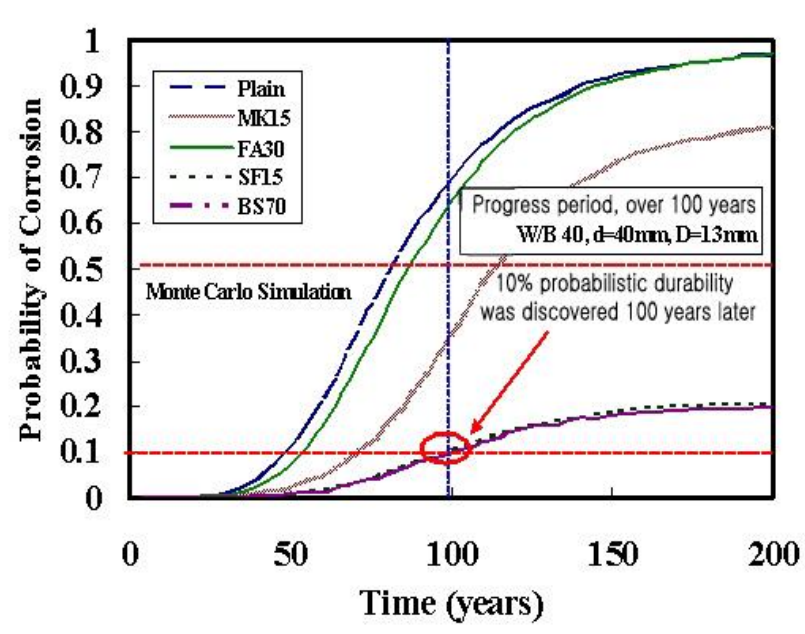

Fig .14. Durability failure possibility according to time

\section{v. CONCLUSION}

In this paper, based on experimental results of chloride diffusion coefficients and Monte Carlo method, the service of concrete structure incorporating different mineral components, such as fly ash (FA), blast furnace slag (BS), silica fume (SF) and metakaolin (MK) was predicted. The proposed model incorporates the statistical nature of chloride induced corrosion of reinforced concrete and can be used to evaluate the time of first repair and rehabilitation of concrete structures.

This study obtained a DPC equation with a W/C using the chloride ion diffusion coefficient and time dependent coefficient (n) calculated by the experiment. It proposes an estimation equation for the chloride ion diffusion coefficient according to the blending ratio of admixtures, using the chloride ion diffusion coefficient of the plain concrete and admixture blended concrete. Large differences of 20 , 40 , and 160 years at a $10 \%$ probabilistic durability failure rate were evident by varying the time dependent index to $0.0,0.4$, and 0.8 under the same conditions of the probabilistic durability life test. It was clear that the time dependent index significantly affected the evaluation of the durability life. Thus, it is necessary to precisely calculate the time dependent index.

\section{ACKNOWLEDGEMENT}

This work was supported by Sustainable Building Research Center Hanyang University, which was funded by the SRC/ERC program of MOST (\#R112005-056-04003-0). This paper is an extended abstract that was published in Korea by AlK.

\section{REFERENCES}

[1] P. Kumar Metha (2006). ConcreteMicrostructure, Properties and Materials. MaGraw-Hill, New York.

[2] Vagelis G. Papadakis (2000). Effect of supplementary cementing materials on concrete resistance against carbonation and chloride ingress. Cem Concr Res 30: 291-299.

[3] Erik P. Nielsen, Mette R. Geiker (2003) Chloride diffusion in partially saturated cementitious material. Cem Concr Res 33: 133-138.

[4] Sang-Hun Han (2007) Influence of diffusion coefficient on chloride ion penetration of concrete structure. Constr Buil 21:370-378.

[5] Ha-won Song, Jong-Chul Jang, Velu Saraswathy, Keun-Joo Byun (2007) An estimation of the diffusivity of silica fume concrete. Bldg Envir 42:1358-1367.

[6] Dongseok Kim, Hanseung Lee, Seongmin Lee, Xiaoyong Wang.(2007) A study on the evaluation of probabilistic durability life for RC Structures deteriorated by chloride ion, Advances in fracture and damage mechanics $\mathrm{VI}$, FDM 2007, Portugal, edited by J.Alfaiate, M.H.Aliabadi, M.Guagliano, L.Susmei, pp.417421.

[7] Trevor J. Kirkpatrick, Richard E. Weyers , Christine M. Anderson-Cook, Michael M. Sprinkel (2002) Probabilistic model for the chloride-induced corrosion service life of bridge decks, Cem Concr Res 32 :1943-1960.

[8] Mchael P. Enright and Dam M. Frangopol (1998) Probabilistic analysis of resistance degradation of reinforced concrete bridge beams under corrosion, Eng Struct 20: 960-971.

[9] Y. Liu, R.E. Weyers (1998) Modeling the time-tocorrosion cracking in chloride contaminated reinforced concrete structures, $\mathrm{ACI}$ Mater. J.95: 675- 681.

[10] M.H. Kalos, P.A. Whitlock (1986) Monte Carlo Methods: Volume I. Basics, Wiley, New York. 